\title{
Effects of Heat Treatment on the Impact and Hardness Properties of Mild Steel [ASTM 36] Lap Welded Joint
}

\author{
O. M. Ikumapayi ${ }^{1}$, E. T. Akinlabi ${ }^{2}$, V. O. Anyoha ${ }^{1}$, I. D. Uchegbu ${ }^{1}$, O. L. Rominiyi ${ }^{1}, H . A$. Benjamin $^{1}, S . A$. Akinlabi $^{3}$
}

${ }^{1}$ Department of Mechanical and Mechatronics Engineering, Afe Babalola University, Ado Ekiti, 360101, Nigeria
2Pan African University of Life and Earth Sciences (including Health and Agriculture), Ibadan, Nigeria.
${ }^{2}$ Department of Mechanical Engineering Science, University of Johannesburg, 2006, South Africa
${ }^{3}$ Department of Mechanical Engineering, Butterworth Campus, Walter Sisulu University, South Africa

\begin{abstract}
ASTM A36 is the most used type of mild steel especially in construction and manufacturing industry. Welding process is regularly employed to fix the crack that usually occurs in low carbon mild steel after a long time use especially in construction industry. In this study, the effects of heat treatment on the mechanical properties on mild steel [ASTM A36] lap welded joint were investigated. Seven pieces of 60 $\mathrm{mm} \times 300 \mathrm{~mm}$ mild steel bar were used for this research. Five samples were heat treated in an electric muffle furnace and soaked at $600^{\circ} \mathrm{C}$ for 65 minutes. Two samples were cooled in air and furnace while the remaining three were rapidly quenched in water, spent engine oil and diesel oil each. Hardness and Impact tests specimens were made from the control (as received) sample and the various heat-treated samples. The specimens were joined together using E6361 mild steel arch welding electrode, lap welding joints and Shielded Metal Arc Welding (SMAW). Hardness test and impact test are used to delineate the mechanical properties for heat treated welded specimens and control specimens. It was established from the research work that Brinel Hardness Number (BHN of ASTM A36 lap welded joint cooled/quenched in different media increased it significantly in the Heat affected Zone (HZ) in all the quenching media. There is also a substantial increase in both Impact Energy (IE) and Impact Strength (IS) of heat-treated ASTM A36 lap welded joint when cool/quenched in the air, furnace, water and spent engine oil.
\end{abstract}

\section{Introduction}

ASTM 36 is a special metal and the most commonly used mild and hot-rolled steel. Apart from iron, it contains negligible percentage of other alloy elements which enhances it relative affordability, weldability, machinability and toughness when compared with other steels. Normally low carbon steel (mild steel) is widely used in construction industries especially for bridge frame. The bigger the bridge to be built, the larger the force that will be required to hold by the frame bridge, therefore heat treatment will enhance the hardness properties of the material [ASTM 36] as well as it impacts resistance. As the age of bridge increases, some defects like crack will happen [1]. To prevent failure, welding process must be carried out, but it is important to determine the best welding joint technique to hold the crack. Hence, this study will help to develop new technologies in which hardness and impact strength of mild steel used as a bridge frame in construction industry will be improved through heat treatment and lap joint welding process [2].

Bridge construction is being carried out actively on daily basis in both rural and urban areas. Because it involves the life of the users of the facility, highly level of safety is a major concern that is

\footnotetext{
${ }^{*}$ Corresponding author: ikumapayi.omolayo@abuad.edu.ng
}

given highest priority in the construction activity. Research reviewed that, building and bridge collapse during recent years in Nigeria has been traced to material failure. Hence, the safety factor required in constructing a strong bridge frame largely depends on the type and quality of materials used [3].

Heat treatment and quenching processes can alter the microstructure properties of mild steel and consequently influence it mechanical properties in terms of strength and resistance properties. The importance of using a high-quality material that have good mechanical properties and the ability to withstand high loading forces needed in building a quality bridge frame cannot be over emphasized. Therefore, the study on heat treatment of lap joint welded mild steel is a step in right direction that can lead to development of a new material with improved strength and toughness that is required in construction of bridge frames where it has a laudable application. The rationale for this work is important because it will bring about new revolutionary ideas where it is possible to use heat treated mild steel [ASTM 36] and lap joint welding technique to improve innovations in construction of bridge frames that can withstand high loading force and aid in determine the welding parameters for carrying out effective repair work on defect (crack) that usually occur on bridge frames [4]. 


\subsection{Heat Treatment}

The atomic structure, micro-structure and crystal structure of metals and alloys make up majority of their engineering properties. Mechanical properties in nature are structure sensitive, and their magnitude is heavily influenced by the shape, scale, and distribution of different micro constituents. These properties may be changed by altering the relative proportions of micro constituents [5]. All these can be done in practice through a process called heat treatment. This procedure entails heating the metal or the alloy to a pre-determined temperature, soaking it at that pre-determined temperature for a specific amount of time needed and then quenching or cooling it down. These operations are always performed in solid-state. It may be appropriate to repeat these operations over again in order for the desired characteristics to be imparted. In simple terms, heat treatment is the heating operations and cooling operations of metals or alloys in the solid-state to achieve the desired mechanical properties [6]. The heat treatment of metals is an important process in the final fabrication of many engineering components. Heat treatment can indeed be used for a variety of purposes, which include:

i. To increase ductility of the metal or alloy.

ii. For the refinement of grain size of a metal or alloy.

iii. Improvement of Machinability of the metal or alloy.

iv. To relieve internal stress in metals or alloys.

v. To increase the hardness and tensile strength of a material.

vi. To increase the toughness of a material.

vii. Modification of the magnetic property of a metal or alloy.

viii. Improve the electrical conductivity of a metal or alloy.

The microstructure of a material also affects its mechanical properties. The outcome of a material's mechanical properties after heat treatment is influenced by many factors, some of the factors considered are; the heating time, the soaking time, the cooling rate, the surrounding conditions, etc. The parameters are determined by the heat treatment method, metal type, and component size [7].

\subsection{Types of Heat Treatment}

i. Hardening: Hardening heat treatment necessitates heating to a sufficiently high temperature to dissolve solute-rich precipitates. To avoid re-precipitation, the metal is rapidly cooled, typically by quenching in oil or water. Parts become considerably lighter and stronger as a result and tools and dies achieve the desired wear resistance while remaining tough [8].

ii. Casehardening: Case-Hardening heat treatment process creates a wear resistant surface while maintaining the core's strength and durability. This treatment can be applied to gears, high alloy steel bearings and low carbon steel part, as well as other components, after undergoing machining. This heat treatment is advantageous in some applications because it enables a component to have a core that is very ductile and an outer part that is very rigid and also wear resistant. Consequently, the wear resistance increases but the hardness will not be compromised. It is suitable for different ranges of applications involving pressure along with wear and tear [9].

iii. Annealing: Annealing is a heating and holding process used to alter the properties of a metal such as steel, aluminum or brass. This procedure helps the metal become more ductile while at the same time lowering the level of hardness to improve machinability. This process improves the ductility of the metal at the same time lowering the hardness in order to improve its machinability and make the metal more workable. Depending on the annealing temperature, heat treatment can be divided into three different classes: full annealing, partial annealing, and critical annealing.

iv. Normalizing: This process is a steel annealing process where the steel is heated to about $150-200^{\circ} \mathrm{F}$, higher than in annealing, and held long enough for the transformation to occur at the critical temperature. Steel handled in this manner must be cooled in air. In normalization, heat treatment makes the grains smaller and austenitic while cooling in the air makes the grains more refined and ferritic. This procedure improves the ductility, strength, and machinability of the steel. The normalization technique is applied to ferrous metals only. The end goal of this process is to improve the hardness of the steel, alleviate internal stresses, and refine grain size [10].

v. Tempering: This is a technique for modifying metallic properties, particularly steel, by heating it to a very high temperature but below the melting point and then cooling it, typically in air. This process has the effect of increasing the toughness of the material by reducing internal stresses and brittleness. Temperatures for tempering may vary considerably depending on the kind of steel and designed application [11].

\section{Materials and Methods}

A $6 \mathrm{~mm}$ thick and $50 \mathrm{~mm} \times 1200 \mathrm{~mm}$ ASTM A36 (Mild Steel) bar was purchased prom local iron and steel market in Ado-Ekiti. 50 pieces of $12 \mathrm{~mm}$ x $60 \mathrm{~mm}$ samples were cut from the purchased mild steel and labeled as shown in Table 1 for further experimental work. Two litters each of water, spent engine oil and spent vegetable oil were also sourced locally for the experimental work. The mechanical properties of the control sample $\left(\mathrm{D}_{\mathrm{C}}\right)$ as adopted from ASTM International is shown in Table 2 [12]. 
Table 1: ASTM A36 Sample and other Materials

\begin{tabular}{|c|c|c|c|}
\hline SN & Label & $\begin{array}{l}\text { Cooling } \\
\text { Quenching } \\
\text { Medium }\end{array}$ & Quantity \\
\hline 1 & $\mathrm{D}_{\mathrm{A}}$ & Air & 8 (4 pairs) \\
\hline 2 & $\mathrm{D}_{\mathrm{D}}$ & $\begin{array}{l}\text { Spent vegetable } \\
\text { oil }\end{array}$ & 8 (4 pairs) \\
\hline 3 & $\mathrm{D}_{\mathrm{E}}$ & Spent engine oil & 8 (4 pairs) \\
\hline 4 & $\mathrm{D}_{\mathrm{F}}$ & Furnace & 8 (4 pairs) \\
\hline 5 & $\mathrm{D}_{\mathrm{W}}$ & Water & 8 (4 pairs) \\
\hline 6 & $\mathrm{D}_{\mathrm{C}}$ & Control Sample & 8 (4 pairs) \\
\hline 7 & $\mathrm{H}_{2} \mathrm{O}$ & Water & 2 liters \\
\hline 8 & $\begin{array}{l}\text { Black } \\
\text { Oil }\end{array}$ & Spent engine oil & 2 liters \\
\hline 9 & $\begin{array}{l}\text { Power } \\
\text { Oil }\end{array}$ & $\begin{array}{l}\text { Spent vegetable } \\
\text { oil }\end{array}$ & 2 liters \\
\hline
\end{tabular}

Table 2: Mechanical Properties of ASTM A36

\begin{tabular}{|l|l|}
\hline Mechanical Properties & Metric Unit \\
\hline Tensile Strength, Ultimate & $400-550 \mathrm{MPa}$ \\
Tensile Strength, Yield & $250 \mathrm{MPa}$ \\
Elongation at Break (in 200 & $20.0 \%$ \\
mm) & \\
Elongation at Break (in 50 & $23.0 \%$ \\
mm) & \\
Modulus of Elasticity & $200 \mathrm{GPa}$ \\
Density & $7.85 \mathrm{~g} / \mathrm{c}_{\mathrm{m}}{ }^{3}$ \\
Poissons Ratio & 0.260 \\
Shear Modulus & $79.3 \mathrm{GPa}$ \\
\hline
\end{tabular}

\subsection{Heat Treatment Processes}

Eight specimens were separated as the unheated control sample $\left(D_{C}\right)$ as shown in Table 1 . An electric muffle furnace with a maximum temperature capacity of $1200^{\circ} \mathrm{C}$ was used to heat treat the specimens in batches according to their labels and cooling/quenching medium. $\mathrm{D}_{\mathrm{W}}$ specimens were heat treated at $600^{\circ} \mathrm{C}$, the specimens were soaked in that temperature for 65 minutes before quenching them in water. The procedure was repeated for other samples: $D_{E}$ and $D_{D}$ specimens were quenched in spent engine oil and vegetable oil respectively while $\mathrm{D}_{\mathrm{A}}$ was cooled in the air and $\mathrm{D}_{\mathrm{F}}$ specimens in the furnace.

\subsection{Welding Process}

Four pairs each from the specimens made from the various heat treated and unheated control samples were joined together using lap welding technique (See Figure 1). A Shielded Metal Arc Welding (SMAW) was employed at a current of $90 \mathrm{~A}$ and a voltage of $220 \mathrm{~V}$. Two samples were placed one over another and then welded on both sides with gauge 10 arch welding electrode for mild steel; welding titanium type. The E6013 electrode was used for this welding process. The devices used for the lap welding and their classifications are as shown in Table 3. Figure 1 shows the welded samples at different quenching and cooling media.

Table 3: Classification of Lap Welding Parameters for ASTM A36 Specimens

\begin{tabular}{|c|c|c|}
\hline SN & Device & Classification \\
\hline 1 & $\begin{array}{l}\text { Welding } \\
\text { Machine }\end{array}$ & $\begin{array}{l}\text { Maker: } \text { WORXFLEX } \\
\text { ((MMA Welder) } \\
\text { Model: MMA Welder } \\
\text { Type : DC Inverter } \\
\text { Voltage : } 0-220 \mathrm{~V} \\
\text { Current : } 0-160 \mathrm{Amps} \\
\text { Frequency: } 50 \mathrm{~Hz}\end{array}$ \\
\hline 2 & 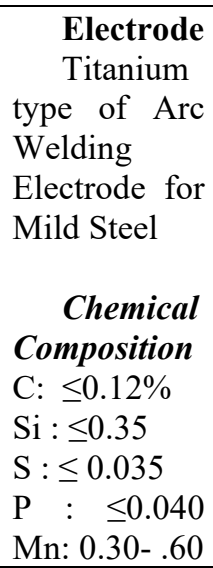 & $\begin{array}{lr}\text { AWS A5.1: } & \text { E6013 } \\
\text { Current: } & 50-100 \mathrm{Amps} \\
\text { Size: } & 2.5 \mathrm{~mm} \text { x } 350 \mathrm{~mm} \\
\text { Polarity: } & \text { AC. DC } \pm \\
\text { Operating } \text { Current: DC AC }\end{array}$ \\
\hline
\end{tabular}
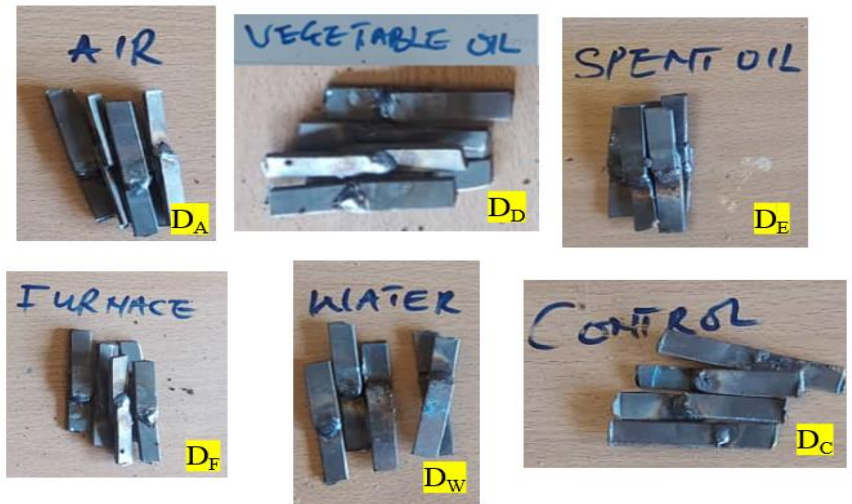

Figure 1: shows the lap-welded specimens at different quenching and cooling media 


\subsection{Mechanical Characterizations}

Hardness and impact tests are used to delineate the mechanical properties for heat treated welded specimens and control specimens. The Welded Zone (WZ), Heat affected Zone (HZ) and Base Meta (BM) hardness value were investigated and compared.

\subsubsection{Hardness Test Process}

Brinell Hardness Test was conducted on the specimens using ATICO Micro Hardness Tester. Three different sections were selected per specimen for hardness test. They are, Welded Zone (WZ), Heat Affect Zone (HZ) and Base Metal (BM). The hardness test procedure goes thus: The diameter (D) of the selected indenter which was $1.6 \mathrm{~mm}$ was recorded, the load selector was set to $100 \mathrm{Kgf}$ and each specimen was selected, cleaned, and made free of dirt and grease. The specimen was placed on the hardness tester anvil and the Welded Zone (WZ) was raised to make secure contact with the indenter. The load was applied on the specimen using the Load/Unload lever, the scale deflector was allowed to rest for 15 seconds before taking the reading. After 15 minutes the machine was unloaded, the anvil lowered, and the specimen was removed. The diameter of indentation $d$ was measured using a microscope and micrometer. The experiment was repeated two times and $\mathrm{d} 1, \mathrm{~d} 2$, and $\mathrm{d} 3 \mathrm{were}$ recorded. The average diameter of indentation for $\mathrm{WZ}$ was calculated using equation 1 while the The Brinell Hardness Number (BHN) was calculated using the formula in equation 2.

$$
\mathrm{d}=\frac{d 1+d 2+d 3}{3}(\mathrm{~mm})
$$

$$
\mathrm{BHN}=\frac{P}{\pi D / 2(D-(\sqrt{D 2}-d 2))}
$$

\subsubsection{Impact Test Process}

Impact test is a practical assessment of brittle fracture of metals and is also used as an indicator to determine suitable service temperature. ATICO Charpy Impact Tester was used to carry out the test. Before the experiment, a standard $45^{\circ} \mathrm{V}$-notch of $2 \mathrm{~mm}$ depth and a $0.25 \mathrm{~mm}$ root radius was made at the center of each specimen. The Charpy Impact test procedure was then carried out; thus, each specimen was selected and cleaned with mentholated spirit. The scale pointer was set to zero position to correct parallax error. One of the specimens was placed in the impact testing machine's vice in such a way that V-notch is facing away from the hammer and in such a way that the hammer strikes the back of the notch at the center of the V-notch. The pendulum was released using the release mechanism and the readings of the impact energy (in joules) directly from the scale was noted. The pendulum was returned to its locked position. The average Impact Absorbed Energy 'IE' (in Joules) and Impact Strength 'IS' (in Joules $/ \mathrm{m}^{2}$ ) for each ASTM A36 mild steel samples were calculated using equations 3 and 4 respectively.

$$
\begin{gathered}
I E=\frac{E 1+E 2+E 3}{3} \\
I S=\frac{I E 0}{A} \quad \ldots \ldots
\end{gathered}
$$

Where $\mathrm{A}$ is the area of the impact specimen $A=L \times B \times H\left(\mathrm{~m}^{2}\right)$

\section{Results and Discussions}

The results obtained from the hardness and impact tests conducted on the heat-treated lap joint ASTM A36 specimens are presented in this section.

\subsection{Hardness Test Result}

The result of the Micro-Brinell Hardness Test of WZ, $\mathrm{HZ}$ and $\mathrm{BM}$ for specimens quenched in water (DW), spent engine oil (DE) and spent vegetable oil (DD), as well as specimens cooled in Air (DA) and in the Furnace (DF) are shown in Table 4. The Brinell Hardness Number (BHN) for each specimen was derived using equation 2. The comparison results are graphically presented in Figure 2.

$$
\begin{gathered}
\mathrm{BHN}=\frac{\mathrm{P}}{\pi D / 2(D-(\sqrt{D 2}-d 2))} \\
B H N=\frac{B N 1+B N 2+B N 3}{3}
\end{gathered}
$$


Table 4: Result of Hardness Test for Heat-Treated ASTM A36 Lap Welded Joint

\begin{tabular}{|c|c|c|c|c|c|}
\hline $\mathbf{S} / \mathbf{N}$ & Quenching/Cooling Medium & BN1 & BN2 & BN3 & BHN \\
\hline \multicolumn{6}{|c|}{ Water (Dw) } \\
\hline 1. & $\mathrm{HZ}$ & 54 & 50 & 48 & 76 \\
\hline 2. & WZ & 32 & 34 & 33 & 33 \\
\hline 3. & $\mathrm{BM}$ & 41 & 38 & 40 & 39.6 \\
\hline \multicolumn{6}{|c|}{ Spent Engine Oil $\left(D_{E}\right)$} \\
\hline 4. & $\mathrm{HZ}$ & 70 & 72 & 74 & 72 \\
\hline 5. & WZ & 46 & 40 & 47 & 44.3 \\
\hline 6. & $\mathrm{BM}$ & 40 & 39 & 41 & 39.6 \\
\hline \multicolumn{6}{|c|}{ Spent Vegetable Oil $\left(D_{D}\right)$} \\
\hline 7. & $\mathrm{HZ}$ & 66 & 81 & 61 & 69 \\
\hline 8. & WZ & 34 & 39 & 41 & 38 \\
\hline 9. & $\mathrm{BM}$ & 34 & 32 & 37 & 34 \\
\hline \multicolumn{6}{|c|}{ Air Cooled $\left(D_{A}\right)$} \\
\hline 10 & $\mathrm{HZ}$ & 65 & 68 & 68 & 67 \\
\hline 11 & WZ & 40 & 40 & 36 & 38.6 \\
\hline 12 & $\mathrm{BM}$ & 28 & 32 & 34 & 34.6 \\
\hline \multicolumn{6}{|c|}{ Furnace Cooled (DF) } \\
\hline 13 & $\mathrm{HZ}$ & 55 & 54 & 54 & 54.33 \\
\hline 14 & $\mathrm{WZ}$ & 33 & 38 & 36 & 35.67 \\
\hline 15 & $\mathrm{BM}$ & 30 & 31 & 29 & 30.33 \\
\hline \multicolumn{6}{|c|}{ Control $\left(\mathrm{D}_{\mathrm{C}}\right)$} \\
\hline 16 & $\mathrm{HZ}$ & 42 & 46 & 44 & 44.00 \\
\hline 17 & WZ & 58 & 60 & 64 & 60.70 \\
\hline 18 & BM & 45 & 44 & 45 & 44.60 \\
\hline
\end{tabular}

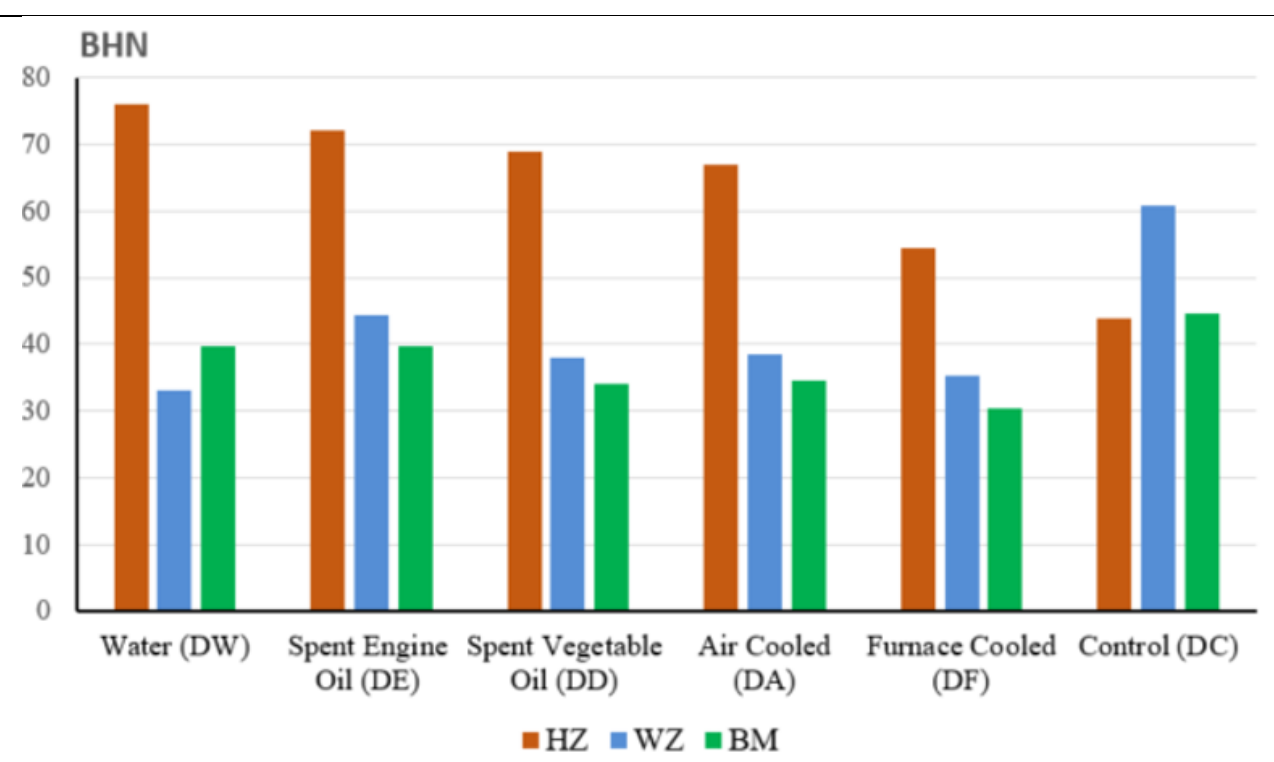

Figure 2: Comparison of Hardness Properties of Heat-Treated ASTM A36 Lap Welded Joint Quenched in Different Media 
Figure 2 shows the comparison of the effect of heat treatment on the BHN of ASTM A36 cooled/quenched in different media. It was revealed that the $\mathrm{BHN}$ increased significant in the Heat affect Zones (HZ) irrespective of the cooling/quenching medium with the highest $\mathrm{BHN}$ recorded in $\mathrm{D}_{\mathrm{W}}$ specimen followed by $\mathrm{D}_{\mathrm{E}}$, $\mathrm{D}_{\mathrm{D}}, \mathrm{D}_{\mathrm{A}}$ and $\mathrm{D}_{\mathrm{F}}$ specimens. The heat treatment did not have any significant effect on the BHN of the Welded (fusion) Zone and the Base Metal (BM). Unlike control samples in which there was not quenching medium, the highest $\mathrm{BHN}$ was noted at $\mathrm{WZ}$ while there was no significant difference in the $\mathrm{HZ}$ and $\mathrm{BM}$ of the Dc samples. This might be as a result of the fact that there was no quenching or cooling media.

\subsection{Impact Test Result}

Table 5 shown the result of the Charpy Impact Test conducted on the heat-treated ASTM A36 Lap Welded Joint quenched in various media compared to that of the Control (C) sample. The Impact Absorbed Energy (IE) in Joules, Impact Strength (IS) in Joules $/ \mathrm{m}^{2}$ and Area (A) in $\mathrm{m}^{2}$ of the specimens were calculated using equations 3, 4 and 5 respectively. In which the length was noted to be $55 \mathrm{~mm}$, breadth $10 \mathrm{~mm}$ and the height was $6 \mathrm{~mm}$. In this case, the area was computed to be 3.3 $\mathrm{m}^{2}$. The comparison results of the Charpy Impact Absorbed Energy (IE) for all the welded samples are presented in Figure 3 while the Impact strength is depicted in Figure 4.

Table 5: Impact Test Result of ASTM A36 Lap Welded Joint Quenched in Various Media

\begin{tabular}{|c|c|c|c|c|c|}
\hline $\mathbf{S} / \mathbf{N}$ & Quenching/Cooling Medium & $\mathrm{IE}_{1}$ & $\mathrm{IE}_{2}$ & $\operatorname{Avg} \operatorname{IE}(\mathrm{J})$ & IS $\left(\mathrm{J} / \mathrm{m}^{2}\right)$ \\
\hline 1. & Water $\left(\mathrm{D}_{\mathrm{W}}\right)$ & 72.00 & 74.00 & 73.00 & 22.12 \\
\hline 2. & Spent Engine Oil $\left(\mathrm{D}_{\mathrm{E}}\right)$ & 70.00 & 72.00 & 71.00 & 21.52 \\
\hline 3. & Spent Vegetable Oil $\left(\mathrm{D}_{\mathrm{D}}\right)$ & 63.00 & 61 & 62.00 & 18.79 \\
\hline 4 & Air Cooled $\left(\mathrm{D}_{\mathrm{A}}\right)$ & 68.00 & 69.00 & 68.50 & 20.76 \\
\hline 5 & Furnace Cooled $\left(\mathrm{D}_{\mathrm{F}}\right)$ & 70.00 & 74.00 & 72.00 & 21.81 \\
\hline 6 & Control $\left(\mathrm{D}_{\mathrm{C}}\right)$ & 64.00 & 62.00 & 63.00 & 19.09 \\
\hline
\end{tabular}

\section{IE (J)}

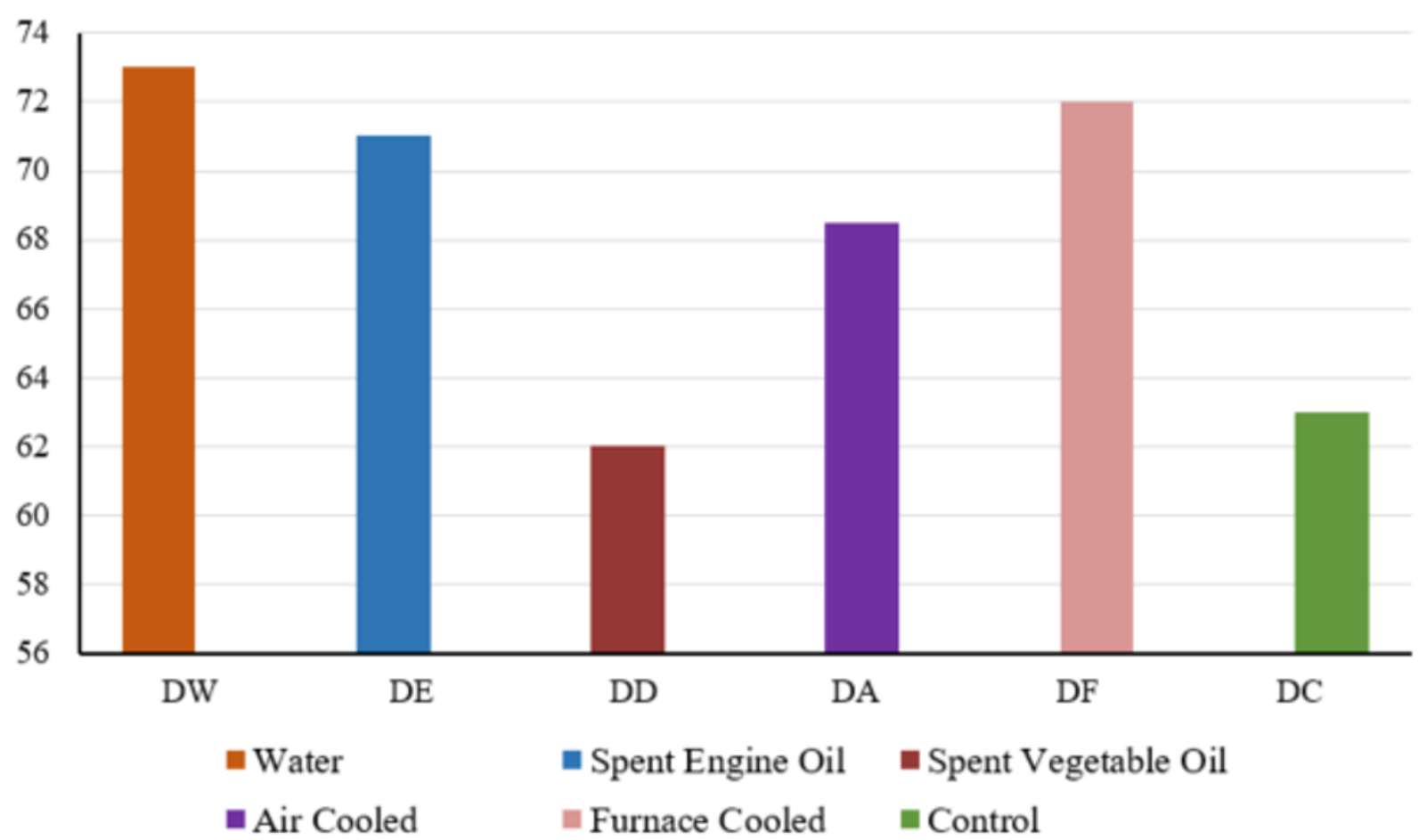

Figure 3: Comparison of Impact Absorbed Energy (IE) of Heat-Treated ASTM A36 Lap Welded Joint Quenched in Different Media 


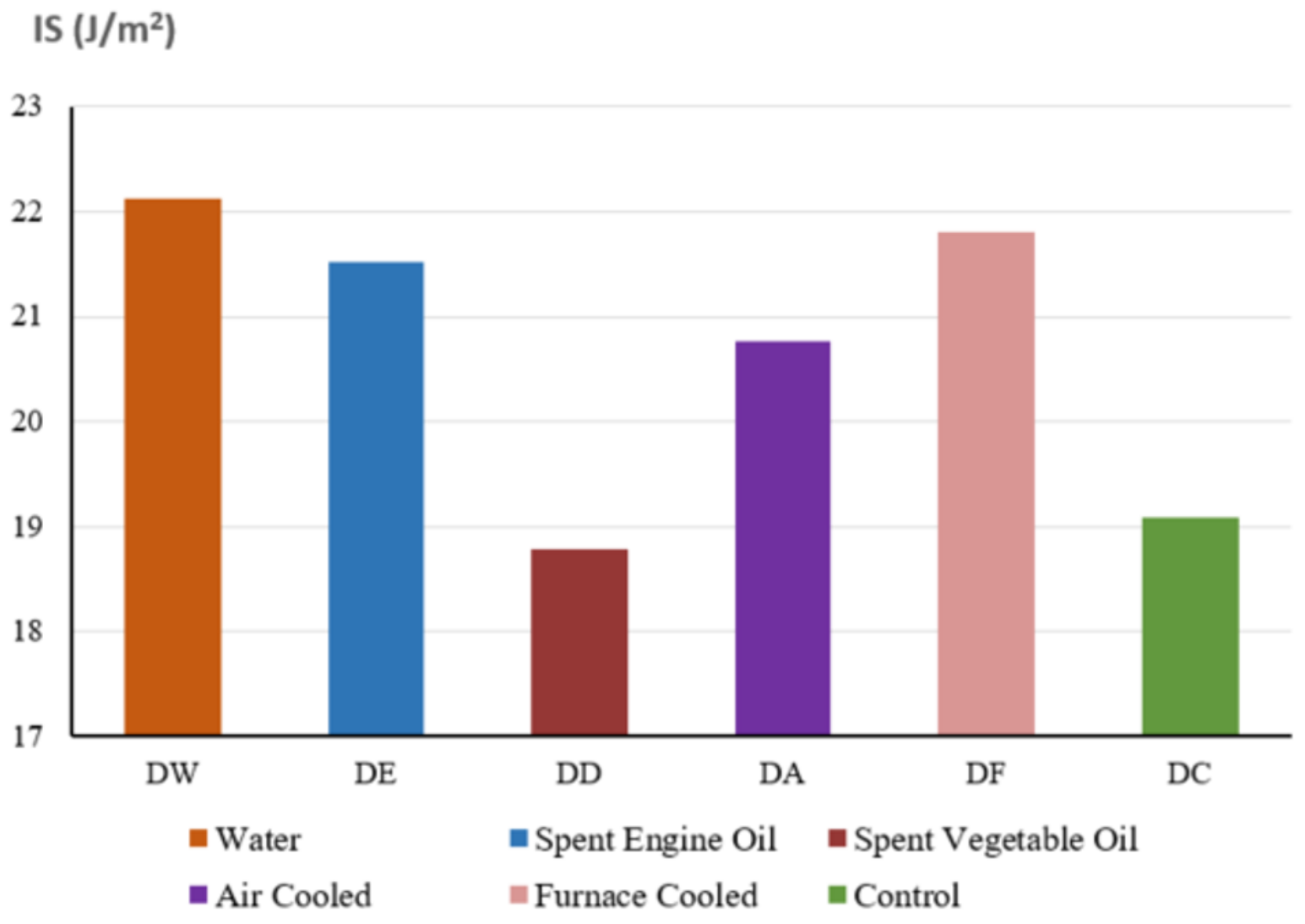

Figure 4: Comparison of Impact Strength (IS) of Heat-Treated ASTM A36 Lap Welded Joint Quenched in Different Media

Figure 3 shown the comparison of Impact absorbed Energy (IE) of heat-treated ASTM A36 lap welded joint quenched in different media while Figure 4 shown the comparison of effect of heat treatment on Impact Strength (IS) of ASTM A36 Lap welded joint quenched in different media. Both figures revealed that heat treatment substantially increase the IE and IS of ASTM A36 lap welded joint quenched in water (DW) by $16 \%$ followed by DF (14.2\%), DE (12.7\%) and DA (8.7\%) specimens. It was also revealed that IE and IS reduced in DD specimen by $1.6 \%$.

\section{Conclusion}

It was established from this research work that heat treatment of ASTM A36 lap welded joint cooled/quenched in different media increased it Brinel Hardness Number (BHN) in the Heat affected Zone (HZ) and reduced in Welded Zone (WZ) also known as fusion zone. Another commendable achievement of this study was establishing the effect of heat treatment on the Impact absorbed Energy (IE) and Impact Strength (IS) of ASTM A36, when quenched in different media. From the study it was established that both IE and IS increased substantially in heat treated ASTM A36 lap welded joint when cool/quenched in the air, furnace, water and spent engine oil. Using spent vegetable oil as quenching medium reduce both the IE and IS of heattreated ASTM lap welded joint.

\section{References}

1. Ikumapayi, O. M., Okokpujie, I. P., Afolalu, S. A., Ajayi, O. O., Akilabi, E. T., Bodunde, O. P. IOP Conf. Series: Materials Science and Engineering 391, 012007, (2018).

2. P. Preedawiphat, N. Mahayotsanun, K. Sangoen, M. Noipitak, P. Tuengsook, S. Sucharitpwatskul, K.Dohda, , Coatings, 10, 844. (2020).

3. O. M. Ikumapayi, E. T. Akinlabi, , S. O. Fatoba, R. A. Kazeem, S. O.Afolabil, A. O. M. Adeoye, S. A. Akinlabi, Advances in Material Science and Engineering, LNME, 150, (2021).

4. S.A. Afolalu, O.M. Ikumapayi, T.S. Ogedengbe, M.E. Emetere, Journal of Composite and Advanced Materials, 31, 153 (2021)

5. S.A. Padhiar, S. Vincent, Mater. Today Proc., 28, 526 (2020)

6. S.A. Afolalu, O.M. Ikumapayi, M.E. Emetere, S.O. Ongbali. Material today: Proceedings, 44, 2879 (2021). 
7. O. M. Ikumapayi, E. T. Akinlabi, J. D. Majumdar, Surface Topography: Metrology and Properties, 17, 1 (2019)

8. D. M. Kapinga, K. D. Nyembwe, O. M. Ikumapayi, E. T. Akinlabi, Manufacturing Review, 7, 1 (2020)

9. E.T. Akinlabi, O. M. Ikumapayi, O. P. Bodunde, B. A. Adaramola, I. D. Uchegbu, S. O. Fatoba, International Journal on Emerging Technologies 11, 290 (2020).

10. V. Shibe and V. Chawla, Advances in Materials Science and Engineering, 2016, 1 (2016).

11. M K Sarath, K Nagoju, V.Gopinath, International Journal of Engineering Research \& Technology, 2, 09 (2013)..

12. ASTM International. ASTM A36/A36M-19, Standard Specification for Carbon Structural Steel; ASTM International: West Conshohocken, PA, USA, 2019. 